\title{
Strain localization and fabric development in polycrystalline anorthite + melt by water diffusion in an axial deformation experiment
}

\author{
Jun-ichi Fukuda ${ }^{1,2,3^{*}}$ (D) Jun Muto ${ }^{1}$ (1) and Hiroyuki Nagahama ${ }^{1}$
}

\begin{abstract}
We performed two axial deformation experiments on synthetic polycrystalline anorthite samples with a grain size of $\sim 3 \mu \mathrm{m}$ and 5 vol\% Si-Al-rich glass at $900{ }^{\circ} \mathrm{C}$, a confining pressure of $1.0 \mathrm{GPa}$, and a strain rate of $10^{-4.8} \mathrm{~s}^{-1}$. One sample was deformed as-is (dry); in the other sample, two half-cut samples (two cores) with $0.15 \mathrm{wt} \%$ water at the boundary were put together in the apparatus. The mechanical data for both samples were essentially identical with a yield strength of $\sim 700 \mathrm{MPa}$ and strain weakening of $\sim 500 \mathrm{MPa}$ by $20 \%$ strain. The dry sample appears to have been deformed by distributed fracturing. Meanwhile, the water-added sample shows plastic strain localization in addition to fracturing and reaction products composed of zoisite grains and $\mathrm{SiO}_{2}$ materials along the boundary between the two sample cores. Infrared spectra of the water-added sample showed dominant water bands of zoisite. The maximum water content was 1500 wt ppm $\mathrm{H}_{2} \mathrm{O}$ at the two-core boundary, which is the same as the added amount. The water contents gradually decreased from the boundaries to the sample interior, and the gradient fitted well with the solution of the one-dimensional diffusion equation. The determined diffusion coefficient was $7.4 \times 10^{-13} \mathrm{~m}^{2} / \mathrm{s}$, which agrees with previous data for the grain boundary diffusion of water. The anorthite grains in the water-added sample showed no crystallographic preferred orientation. Textural observations and water diffusion indicate that water promotes the plastic deformation of polycrystalline anorthite by grain-size-sensitive creep as well as simultaneous reactions. We calculated the strain rate evolution controlled by water diffusion in feldspar aggregates surrounded by a water source. We assumed water diffusion in a dry rock mass with variable sizes. Diffused water weakens a rock mass with time under compressive stress. The calculated strain rate decreased from $10^{-10}$ to $10^{-15} \mathrm{~s}^{-1}$ with an increase in the rock mass size to which water is supplied from $<1 \mathrm{~m}$ to $1 \mathrm{~km}$ and an increase in the time of water diffusion from $<1$ to $~ 10,000$ years. This indicates a decrease in the strain rate in a rock mass with increasing deformation via water diffusion.
\end{abstract}

Keywords: Anhydrous polycrystalline anorthite, Water diffusion, Griggs-type deformation apparatus, Plastic deformation, Reaction

\section{Introduction}

The deformation of feldspar can control the rheology of the lower-middle crust because of its dominance (e.g., Rutter and Brodie 1988; Kohlstedt et al. 1995; Bürgmann

\footnotetext{
*Correspondence: jfukuda@eps.s.u-tokyo.ac.jp

${ }^{1}$ Department of Earth Science, Tohoku University, 6-3 Aoba-ku, Sendai, Miyagi 980-8578, Japan

Full list of author information is available at the end of the article
}

and Dresen 2008). The deformation mechanisms of feldspar and its microstructures have been investigated through analyses of naturally deformed samples (e.g., Olsen and Kohlstedt 1985; Kruhl 1987; Prior and Wheeler 1999; Jiang et al. 2000; Kruse et al. 2001; Menegon et al. 2008; Raimbourg et al. 2008; Fukuda et al. 2012; Fukuda and Okudaira 2013; Getsinger et al. 2013; Menegon et al. 2015 and references therein) and experimental studies (e.g., Tullis and Yund 1987, 1991; Dimanov 
et al. 1998, 1999, 2000; Heidelbach et al. 2000; Stünitz and Tullis 2001; Rybacki and Dresen 2004; Rybacki et al. 2006, 2008, 2010 and references therein). The flow laws of feldspar were constructed for both dry feldspar and feldspar with water, which reduces the strength of a rock (Dimanov et al. 1999; Rybacki and Dresen 2004; Rybacki et al. 2006).

Many tomographic observations suggest that low seismic velocity zones or electrically high-conductivity zones beneath active faults are related to an enriched distribution of pressurized water (e.g., Ogawa et al. 2001; Okada et al. 2006; Wannamaker et al. 2009; Nakajima et al. 2010; Becken et al. 2011 and references therein). In these zones, it is assumed that water is continuously supplied to rocks, thereby enhancing the strain, strain rate, and reaction mechanisms and causing plastic deformation in regions supplied with water; these regions therefore evolve in both time and space depending on the water supply.

As for the effects of supplied water on rock deformation, several deformation experiments have been conducted on the addition of water into quartz and feldspar as major constituents of the crust (Kronenberg and Tullis 1984; Den Brok and Spiers 1991; Den Brok et al. 1994; Post et al. 1996; Post and Tullis 1998; Stünitz et al. 2003; Vernooij et al. 2006; Chernak et al. 2009). These studies revealed that added water reduces the strengths of samples via the enhancement of dislocation creep, diffusion creep, reaction creep, and/or solution-precipitation creep, which are also associated with the development of microstructures. However, these studies did not focus on or observe the time-dependent development of microstructures or a water distribution.

In this study, we performed water-added deformation experiments on a dry anorthite aggregate and externally added water to a sample during deformation. We accordingly discuss the development of microstructures via water diffusion and reactions under differential stresses. The microstructures are compared with those from an experiment without water. In addition, we analyze the water distribution and discuss the diffusion of water. We also discuss the evolution of the strain rate of a rock mass controlled by water diffusion at various scales and times that are assumed in nature.

\section{Starting material}

Polycrystalline anorthite was obtained from anorthite glass powders with a grain size of $\sim 3 \mu \mathrm{m}$ (Fig. 1). These glass powders were sintered and crystallized under vacuum conditions at $1400{ }^{\circ} \mathrm{C}$. Then, polycrystalline samples were obtained with Raman spectra that show clear An lattice
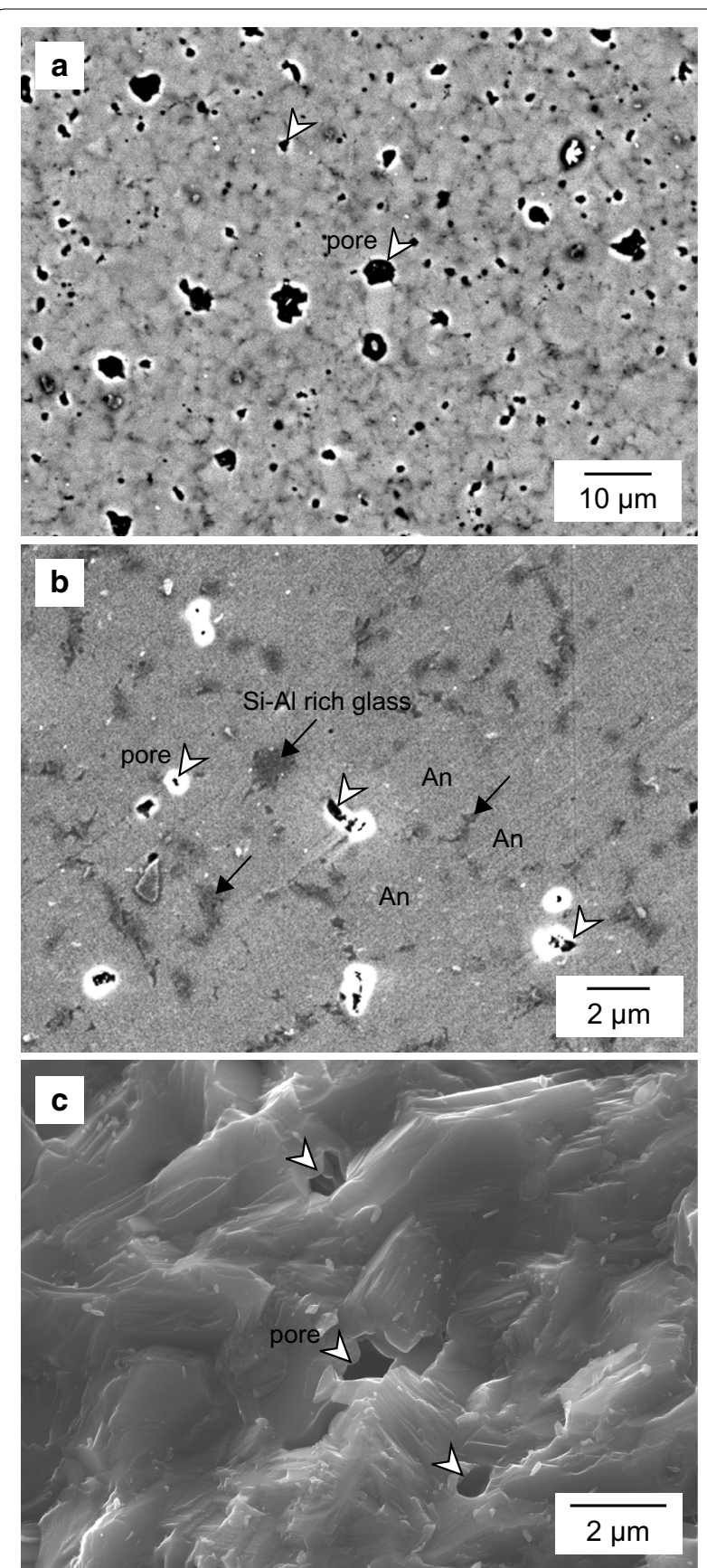

Fig. 1 Characteristics of sintered polycrystalline anorthite ${ }_{100}$ used as the starting material for the deformation experiments. a BSE image of the thin section. Anorthite grains with a size of $3 \mu \mathrm{m}$ (light gray) are surrounded by silica- and aluminum-rich glass (dark gray), which are clearly observed in (b). Small $(\sim 2 \mu \mathrm{m})$ and large pores $(\sim 5 \mu \mathrm{m})$ are black. $\mathbf{b}$ Enlarged image of the thin section. Glass materials (dark gray) with a 5 vol\% developed along the anorthite grain contacts (light gray). c Secondary electron image of a broken surface of the starting material. Representative pores, anorthite grains, and silica- and aluminum-rich glass are indicated 
bands. The samples contain pores with diameters of up to $5 \mu \mathrm{m}$ under backscattered electron (BSE) images and exhibit pore volume ratios reaching $10 \mathrm{vol} \%$ (Fig. 1a). In addition, glass materials of $5 \mathrm{vol} \%$ are included, especially along grain contacts (Fig. 1b). The anorthite grain size traced along the glass materials in the BSE images is $\sim 3 \mu \mathrm{m}$ (equivalent circle diameter). The chemical compositions of the anorthite grains measured using energy-dispersive $\mathrm{X}$-ray spectroscopy (EDS) are $>$ An95, and the glass materials show dominant $\mathrm{SiO}_{2}(36-40 \mathrm{wt} \%)$ and $\mathrm{Al}_{2} \mathrm{O}_{3}$ contents (55-60 wt\%) with a smaller $\mathrm{CaO}$ content $(2-5 \mathrm{wt} \%)$ than the anorthite grains $(\sim 20 \mathrm{wt} \%$ of $\mathrm{CaO})$. The measured composition of the glass materials may include that of any neighboring anorthite grains since the size of the glass materials is $<2 \mu \mathrm{m}$, which is smaller than the spatial resolution of EDS analysis. The contents of other components such as sodium and/or potassium are under the detection limit both in the anorthite grains and in the glass materials. The glass materials may have been formed by the evaporation of calcium components and/or from the incongruent melting of anorthite, which forms a solid phase with a calcium feldspar component and a melt phase with a sodium or potassium feldspar component (although it is under the detection limit), during vacuum crystallization at $1400{ }^{\circ} \mathrm{C}$. The broken surfaces of the samples under a scanning electron microscope (SEM) showed cleavage in the anorthite and small pores (Fig. 1c). The aspect ratio of anorthite is ca. 1.5, and electron backscatter diffraction (EBSD) analysis did not reveal clear crystallographic preferred orientations. An infrared (IR) spectrum of the samples exhibited a weak water absorption band (shown later for the deformed sample), but this band easily disappeared after heating to approximately $100^{\circ} \mathrm{C}$. Therefore, this band must be related to loosely adsorbed atmospheric water.

\section{Experiments}

Two axial deformation experiments were performed using a Griggs-type deformation apparatus for (1) an as-is (dry) sample core with a diameter of $6.2 \mathrm{~mm}$ and a length of $10 \mathrm{~mm}$ and (2) a sample with $0.15 \mathrm{wt} \%$ distilled water added between two 5-mm-long cores. The water surrounded and penetrated the sample during the deformation experiment. The construction of the assembly is based on Chernak et al. (2009). The assembly is shown in Fig. 2. The sample [and the water in experiment (2)] was enclosed in a Pt jacket, which was mechanically sealed during the process of increasing pressure. The Pt jacket was further enclosed in a $\mathrm{Ni}$ jacket. Alumina pistons were placed at the upper and lower parts of the sample. A pressure medium composed of $\mathrm{NaCl}$ was set around the sample and the pistons. A graphite heater was separated from the $\mathrm{NaCl}$ by two fired (dried) pyrophyllites, which were placed around the inner and outer parts of the

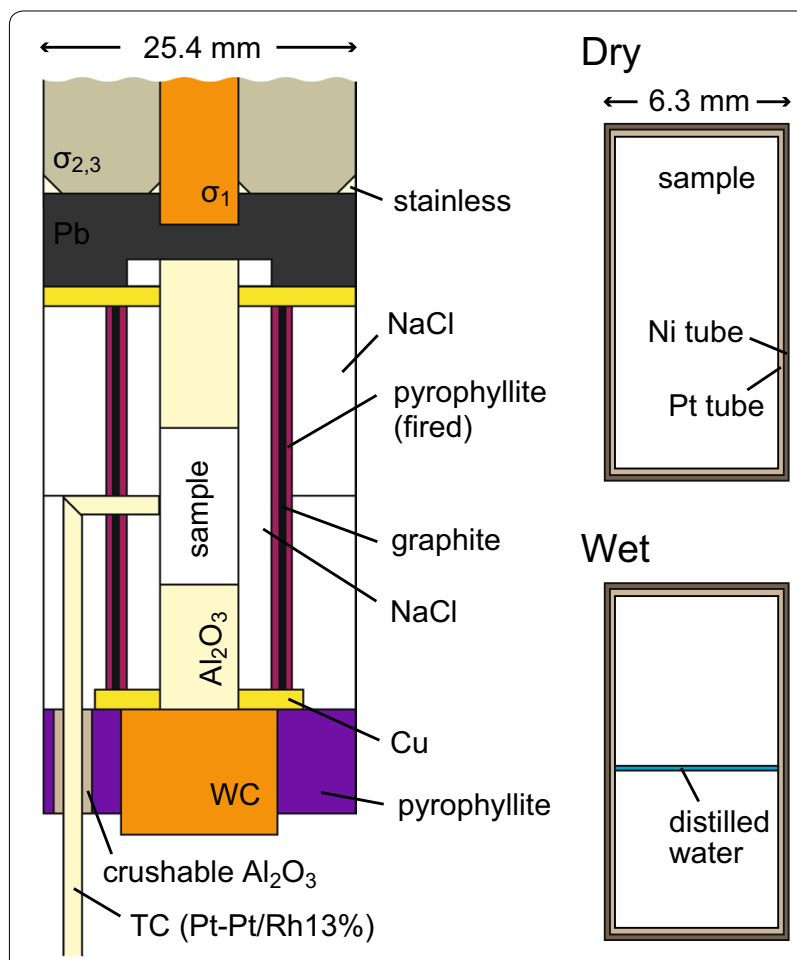

Fig. 2 Schematic diagrams of the whole sample assembly (left) and enlarged inner sample assemblies (right) for the dry and water-added experiments. The water added between the two columns surrounds these columns during the high-pressure and high-temperature experimental conditions

heater. $\mathrm{NaCl}$ was also placed outside the heater as a pressure medium. A thermocouple of $\mathrm{Pt}-\mathrm{Pt} / \mathrm{Rh} 13 \%$ was protected by an alumina tube and set close to the $\mathrm{Ni}$ jacket.

The confining pressure and temperature were carefully raised in the stability field of anorthite and water (Matthews and Goldsmith 1984). The temperature and pressure were raised as follows: from room temperature to $100{ }^{\circ} \mathrm{C}$ at $200 \mathrm{MPa}$, to $200{ }^{\circ} \mathrm{C}$ at $400 \mathrm{MPa}$, to $300{ }^{\circ} \mathrm{C}$ at $800 \mathrm{MPa}$, and finally to $900{ }^{\circ} \mathrm{C}$ at $1 \mathrm{GPa}$. The rate of pressure increase was ca. $100 \mathrm{MPa} / \mathrm{h}$ and was achieved via a hand pump. The rate of temperature increase was ca. $50{ }^{\circ} \mathrm{C} / \mathrm{min}$. After reaching $1 \mathrm{GPa}$ and $900{ }^{\circ} \mathrm{C}$, an axial compression test was immediately performed with a strain rate of $10^{-4.8} \mathrm{~s}^{-1}$ for both experiments. This procedure requires ca. $1 \mathrm{~h}$ for the piston movement before deformation to detect the sample hit point (pre-hit). Then, the samples were deformed for $6 \mathrm{~h}$ for 32\% total strain in the dry experiment and $4 \mathrm{~h}$ for $18 \%$ total strain in the wet experiment. In the wet experiment, water diffused into the sample within a total time of $5 \mathrm{~h}$. The force and displacement data were converted into differential stress and strain values, respectively, according to changes in the sample diameters, corrections for apparatus distortion, and friction within the sample assembly. 
The stress resolution of the apparatus has been estimated to be $\pm 30 \mathrm{MPa}$ in recent papers (Holyoke and Kronenberg 2010; Kido et al. 2016).

The recovered samples were longitudinally cut into halves (i.e., along the axial displacement direction). Thin sections were made from one of those halves for microstructural observations. The other half (ca. $100 \mu \mathrm{m})$ was used for IR spectroscopy analyses. The residual sample pieces in these procedures were used to observe broken surfaces via an SEM.

\section{Analytical methods \\ EBSD measurements}

To measure the crystallographic orientation of the anorthite, we used a Hitachi S-3400N scanning electron microscope equipped with an EBSD analyzer provided by HKL Technology. The analyses were performed for highly polished thin sections with an accelerating voltage of $20 \mathrm{kV}$, a stage current of $1 \mathrm{nA}$, and a working distance of $18 \mathrm{~mm}$ for specimens that were tilted $70^{\circ}$. The EBSD data were analyzed by the HKL Technology Channel 5 software. An index of Kikuchi patterns with a mean angular deviation of $<1^{\circ}$ was accepted as orientation data.

\section{IR measurements}

The transmitted IR spectra were measured using a Fourier transform IR micro-spectrometer (Nicolet iS10, Thermo Scientific). Mapping measurements using an auto XY-stage were taken for the sample recovered from experiment (2). First, a measurement was taken along the direction of axial compression around the upper and lower sample boundaries with a rectangular aperture of $25 \times 50 \mu \mathrm{m}$ (height $\times$ width) and the same step size. Next, a measurement was taken in the direction normal to axial compression apart from the sample boundary with an aperture size of $50 \times 25 \mu \mathrm{m}$ and the same step size. Each spectrum was averaged over 100 scans with a frequency resolution of $4 \mathrm{~cm}^{-1}$ under atmospheric conditions. The background was corrected after each acquisition of 25 spectra. The absorption coefficients for the water absorption bands in the feldspar groups were determined to estimate the water contents following Beran (1987) and Johnson and Rossman (2003), whose methods have been used in, e.g., Dimanov et al. (1998) and Rybacki et al. (2006) for a hot-pressed anorthite aggregate and Fukuda et al. (2012) for natural K-feldspar aggregates. However, in this study, the water contents were calculated from a water-stretching band using the calibration of Paterson (1982), which is independent of the mineral species because the water absorption bands measured in this study include glass and reaction products in addition to anorthite. This calibration approach includes the integral molar absorption coefficient of hydrogen $I\left(\ell / \mathrm{mol} \mathrm{H} \cdot \mathrm{cm}^{2}\right)$ and the mean wavenumber $v_{\text {mean }}$ with $I=150 \gamma\left[3780-v_{\text {mean }}\right]$, where $\gamma$ is an orientation factor of $1 / 3$ assuming an isotropic $\mathrm{OH}$ distribution, any beam direction and no polarization. Our results show that the $v_{\text {mean }}$ values depend on the type of water among the different minerals. The absorption coefficient units of $\mathrm{l} / \mathrm{mol} \mathrm{H} \cdot \mathrm{cm}^{2}$ were converted into $\mathrm{l} / \mathrm{mol} \mathrm{H}_{2} \mathrm{O} \cdot \mathrm{cm}^{2}$ through multiplication by 2 . The water contents were calculated using the Beer-Lambert law and expressed as wt ppm $\mathrm{H}_{2} \mathrm{O}$ using the molar mass of $\mathrm{H}_{2} \mathrm{O}$ and the density of either anorthite or zoisite as the reaction product. The mapping results are displayed as color-contoured images of the calculated water contents.

\section{Results}

\section{Mechanical data}

The mechanical data from the axial compression of the dry and water-added samples were nearly identical within the error of the mechanical resolution of the rig (Kido et al. 2016) (Fig. 3). The total strains for the dry and water-added samples were 32 and $18 \%$, respectively. Assuming elastic strains of $\sim 6 \%$ in these two experiments, the permanent strains are 26 and $12 \%$, respectively. The apparent elastic moduli for the dry and water-added samples determined from the linear elastic slopes of the stress-strain curves are $20.5 \pm 0.5$ and $15.8 \pm 0.3 \mathrm{GPa}$, respectively. These values are remarkably lower than the typical values of anorthite aggregate at our experimental condition $\left(1 \mathrm{GPa}, 900{ }^{\circ} \mathrm{C}\right.$ ) (elastic modulus of $93 \mathrm{GPa}$ calculated by Hacker and Abers 2004). However, note that the measured elastic strain using the above-mentioned Griggs-type deformation apparatus includes inelastic deformation of the sample assembly (mainly of the $\mathrm{Pb}$ piece; Kido et al. 2016) and elastic deformation of the apparatus. The total time of

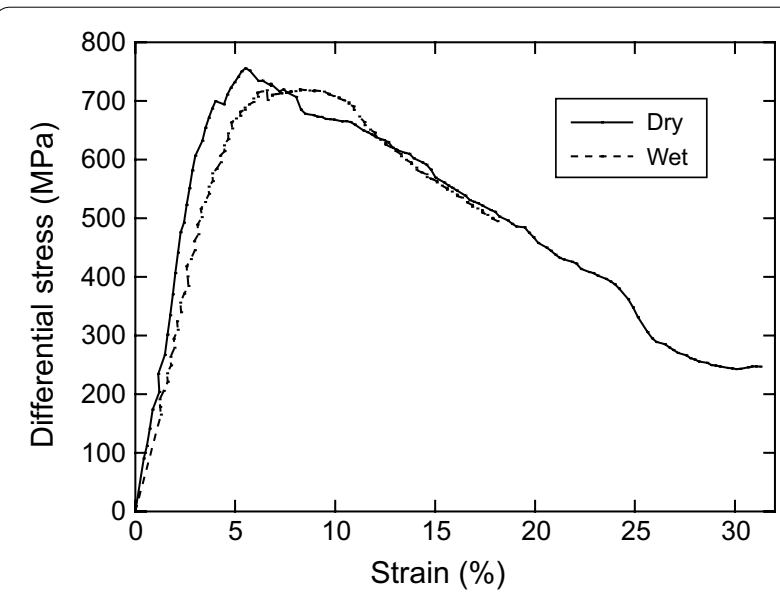

Fig. 3 Stress-strain curve for the dry (solid line) and water-added (dashed line) axial deformation experiments 
deformation experiment for the water-added sample at $900{ }^{\circ} \mathrm{C}$ was approximately $5 \mathrm{~h}(1 \mathrm{~h}$ for pre-hit and $4 \mathrm{~h}$ for deformation), which enabled water to penetrate the sample and the sample to be deformed. The maximum differential stress of the dry sample was $700 \mathrm{MPa}$ at a $6 \%$ strain and that of the water-added sample was $9 \%$. Both samples showed similar strain weakening behaviors after reaching the peak differential stresses.

\section{Microstructural observations}

The microstructures of the dry and water-added samples are obviously different. Figures 4 and 5 show optical micrographs of the dry and water-added samples, respectively. Many fractures are locally developed in the dry sample, and the reduction in the differential stress after reaching the yield strength is likely due to the development of these fractures (Fig. 3). This indicates that cataclastic flow is the dominant deformation mechanism for the dry sample.

Meanwhile, in the water-added sample, outward bulging toward the side of the sample column was observed around the upper and lower sample boundaries (Fig. 5a and the enlarged image in Fig. 5b). The vicinities around some of the fractures as well as the sides of the sample column are transparent with a width of $\sim 200 \mu \mathrm{m}$.
Dark-colored materials of $\sim 30 \mu \mathrm{m}$ were detected along the sample boundary (Fig. 5c), where zoisite grains with sizes up to $50 \mu \mathrm{m}$ were confirmed within a BSE image (Fig. 6a). These zoisite grains are not connected to each other, and each grain exists separately. No compositional changes in either the anorthite grains or the glass were detected. Dark materials exist within and around the zoisite grains within a BSE image. These materials reaching up to $10 \mu \mathrm{m}$ are sometimes connected (Fig. 6b). The chemical compositions of these materials, which were likely formed from reactions, are principally $\mathrm{SiO}_{2}$. A pore reduction, which would transmit light under an optical microscope and correspond to transparent domains (Fig. 5), was observed within a BSE image around the sample boundary in the water-added sample (Fig. 6b). The bulging and reduction of pores in the water-added sample indicate that plastic deformation and the anorthite-water reaction were concentrated around the sample boundary. In addition, very small zoisite grains with high aspect ratios were observed on the surfaces of the anorthite grains (Fig. 6c), as reported in Matthews and Goldsmith (1984). Some vermicular-like features are also shown in Fig. 6d. According to Goldsmith (1982) and Matthews and Goldsmith (1984), the stables phases over 1.2 $\mathrm{GPa}$ and $900{ }^{\circ} \mathrm{C}$ in the $\mathrm{CaO}-\mathrm{Al}_{2} \mathrm{O}_{3}-\mathrm{SiO}_{2}-\mathrm{H}_{2} \mathrm{O}$ system
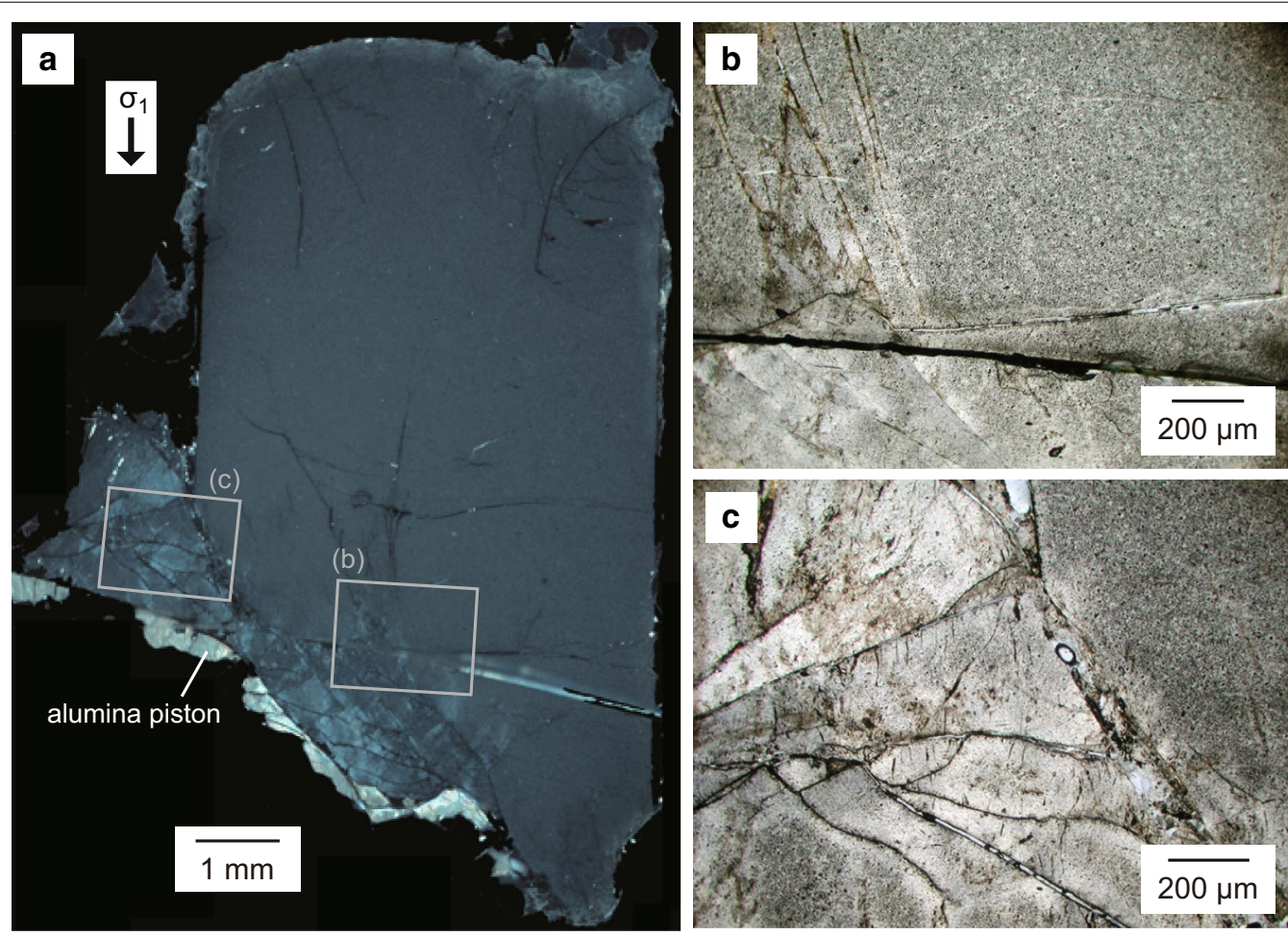

Fig. 4 Optical image of the deformed dry sample. a Image of the entire sample (cross-polarized light). The compression direction $\left(\sigma_{1}\right)$ is shown by an arrow. Cataclastic flow is localized, especially at the bottom of the sample. Rectangles denote the locations for enlarged images $(\mathbf{b})$ and $(\mathbf{c})$. b Fractured area (plane-polarized light). c Strain-localized areas (plane-polarized light) 


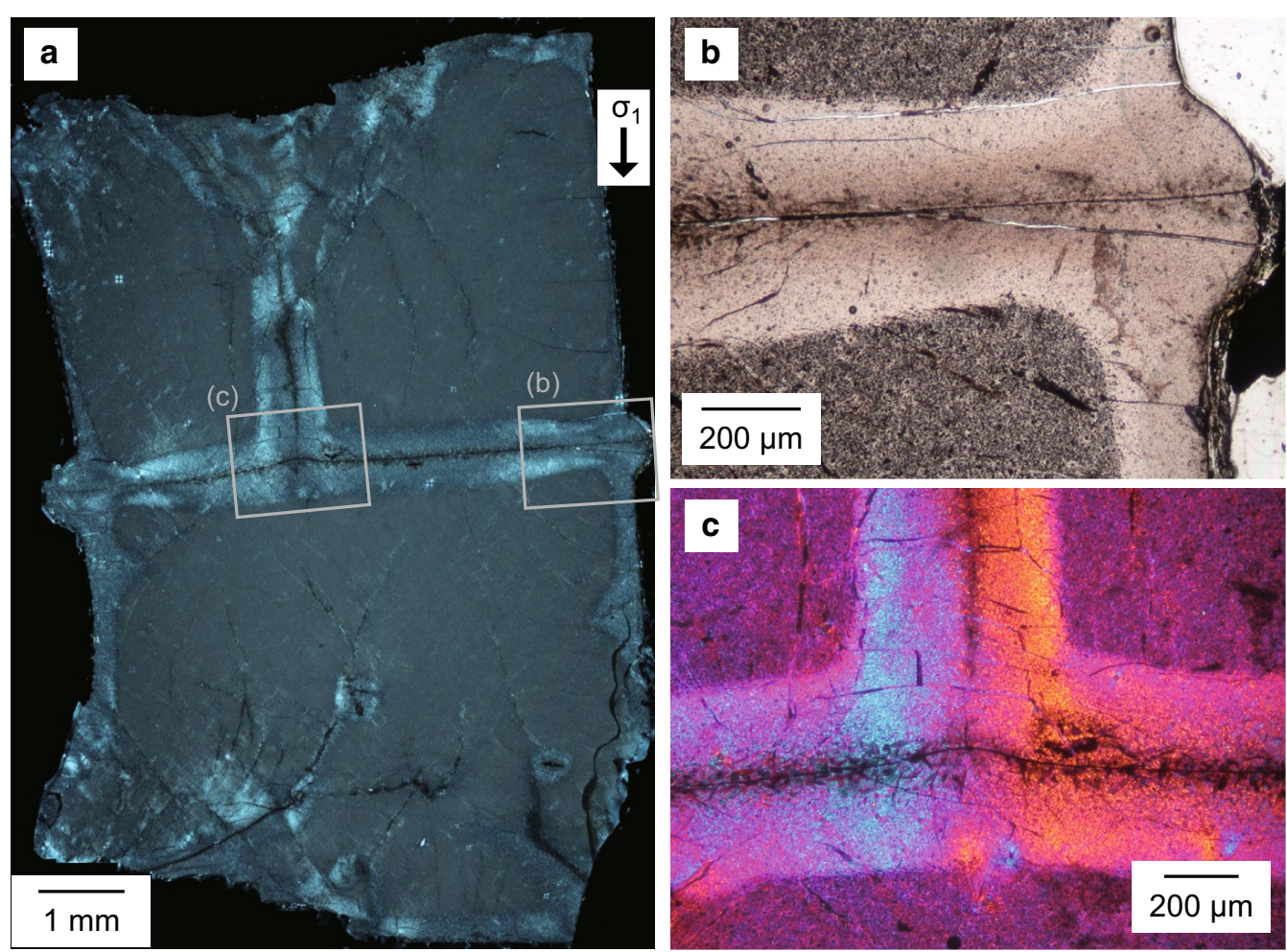

Fig. 5 Optical image of the deformed water-added sample. a Image of the entire sample (cross-polarized light). The compression direction $\left(\sigma_{1}\right)$ is shown by an arrow. Transparent parts can be seen at the upper and lower sample boundaries, the edge of the sample column, and around the fractures with a width of ca. $200 \mu \mathrm{m}$. Bulging can be recognized at the lateral sample boundaries. Rectangles denote the locations for enlarged images (b) and (c). b Bulging part (plane-polarized light). c Sample boundary and upward fracture (cross-polarized light with a gypsum plate). The sample boundary (a few tens of $\mu \mathrm{m}$ ) is especially dusty, which is related to the formation of zoisite (Fig. 6)

are zoisite + kyanite $+\mathrm{H}_{2} \mathrm{O}+$ melt. These pressure and temperature conditions would be caused by a differential stress plus a confining pressure of $1 \mathrm{GPa}$. The possible reaction can be written as follows:

$$
\text { Anorthite }+\mathrm{H}_{2} \mathrm{O} \rightleftharpoons \text { zoisite }+ \text { kyanite }+ \text { melt }
$$

These minerals were observed during the deformation experiment for An54 and An60 in Stünitz and Tullis (2001). Kyanite grains were not observed in the SEM images, similar to the observations by Matthews and Goldsmith (1984). The melt phase in the above reaction would be associated with $\mathrm{SiO}_{2}$ materials, which may be amorphous or crystalline (Fig. 6b).

The area fractions of the zoisite grains visible within the BSE images of the sample slab (e.g., Fig. 6a, b) were determined by outlining grains at an interval of $25 \mu \mathrm{m}$ from the sample boundary (Fig. 7), which corresponds to the step size of the IR spectroscopic measurements. The zoisite fraction is the highest around the boundary (18.3\%), decreases toward the inner part of the sample, and almost disappears at a distance of $250 \mu \mathrm{m}$ from the boundary.

The strain in the bulging part can be calculated from the initial length of the sample and the width of the bulging section. We used a relatively linear sample segment in Fig. 5, where the deformation appears to have been accommodated only by bulging. The difference between the initial sample length $(10.2 \mathrm{~mm})$ and the linear segment in Fig. $5(9.0 \mathrm{~mm})$ gives the initial length of the bulging part $(1.2 \mathrm{~mm})$. The strain calculated from the initial sample length and the linear segment in the deformed sample is consistent with a total permanent strain of $12 \%$ in the mechanical data, which also uses the initial sample length (Fig. 3). The length of the bulging part in the deformed sample corresponds to the width $(0.7 \mathrm{~mm})$ of the transparent portion around the top and bottom sample core boundaries. The calculated strain in the bulging part determined from the initial length of the bulging segment and the length of the transparent portion in the deformed sample is ca. $40 \%$, which is approximately four times the permanent strain of the sample in the mechanical data (Fig. 3). 

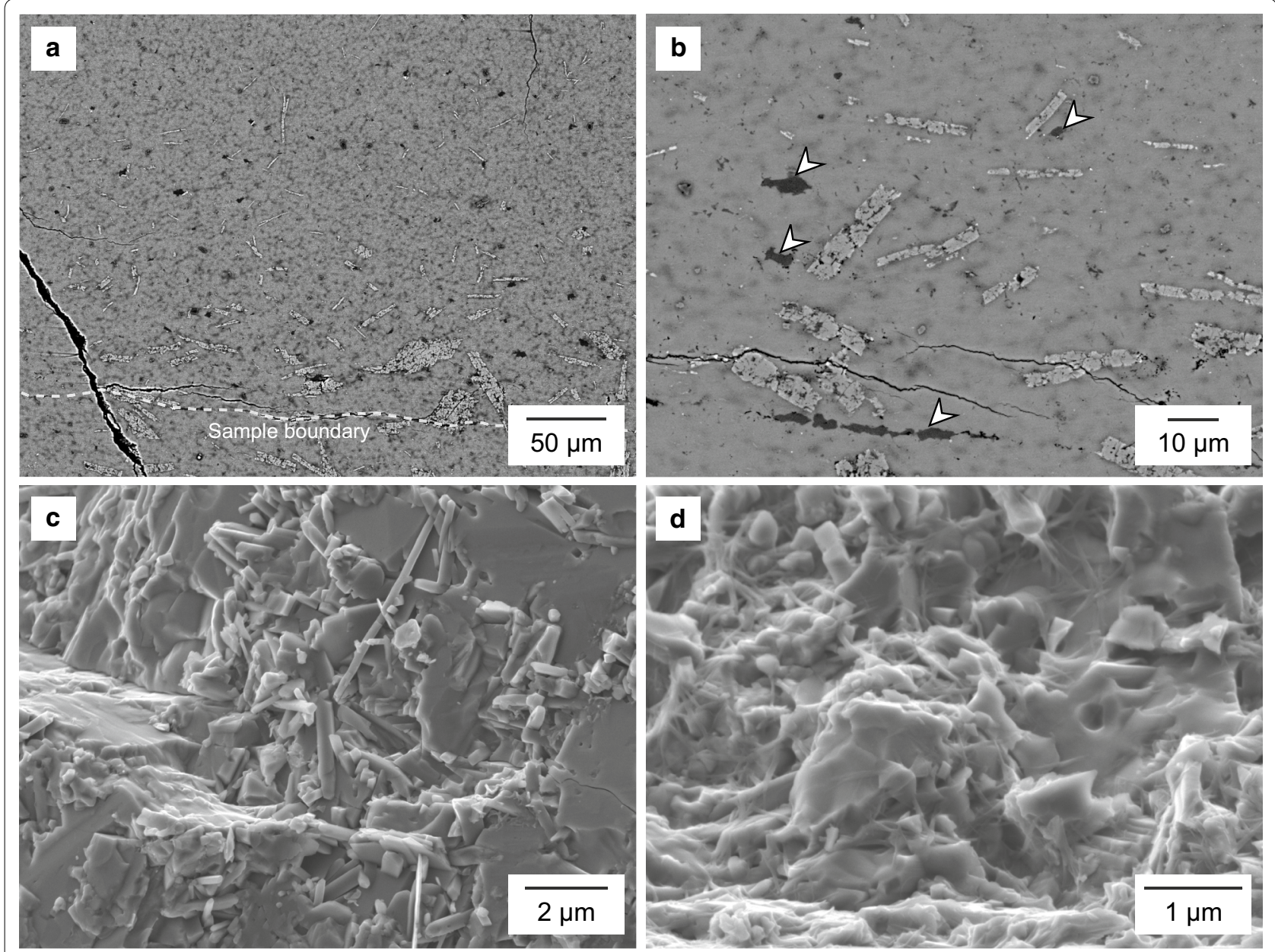

Fig. 6 SEM images of the water-added sample. a BSE image of a polished surface around the upper and lower sample boundaries. The sample boundary is shown as a white dashed line. The grains with a light gray color, a length of $\sim 50 \mu \mathrm{m}$, and an aspect ratio of $\sim 5$ are zoisite, which is seen especially around the sample boundaries. $\mathbf{b}$ Enlarged image of the thin section. Large $\mathrm{SiO}_{2}$ materials are shown in dark gray with arrows. They are sometimes segregated, but they are also seen around grain contacts (slightly darker colors), similar to the initial sample (Fig. 1). A reduction of pores is observed, especially around the bulging and transparent portions (see Fig. 5). c, d Secondary electron images of broken surfaces within approximately $200 \mu \mathrm{m}$ of the sample boundary. Highly elongated grains (lengths of $\sim 5 \mu \mathrm{m}$ and aspect ratios of $\sim 5$ ) are developed on the anorthite grains. Vermicular-like features can also be observed in (d)

\section{EBSD measurements}

EBSD measurements were taken for anorthite grains in the water-added sample (Fig. 8). Grains within a distance of $50 \mu \mathrm{m}$ from the upper and lower sample boundaries were analyzed carefully while avoiding reaction products, which are recognizable within the BSE images. The obtained crystallographic orientations show a random distribution (Fig. 8b).

\section{IR measurements}

IR mapping measurements were taken for the sample boundaries, including the bulging and the inner portions, from the water-added deformation experiment. The results are shown in Fig. 9. High absorbance values from water-stretching bands are seen around the sample boundaries (Fig. 9b) due to the structural hydroxyl of zoisite with representative frequencies at $3185 \mathrm{~cm}^{-1}$ and shoulder bands at 3275 and $2145 \mathrm{~cm}^{-1}$ (Langer and Lattard 1980). In addition to the zoisite bands, a band near $3540 \mathrm{~cm}^{-1}$ may be due to water in the originally included glass (e.g., Stolper 1982) (Fig. 1b) and is clearly different from bands due to adsorbed atmospheric water. Bands under $1800 \mathrm{~cm}^{-1}$ are due to the structural vibrations of feldspar, which are well in accordance with previous studies (Fukuda et al. 2012), and these bands did not significantly change in the mapped area. The intensities in the water bands of the zoisite gradually decreased from the sample boundaries to the inner 


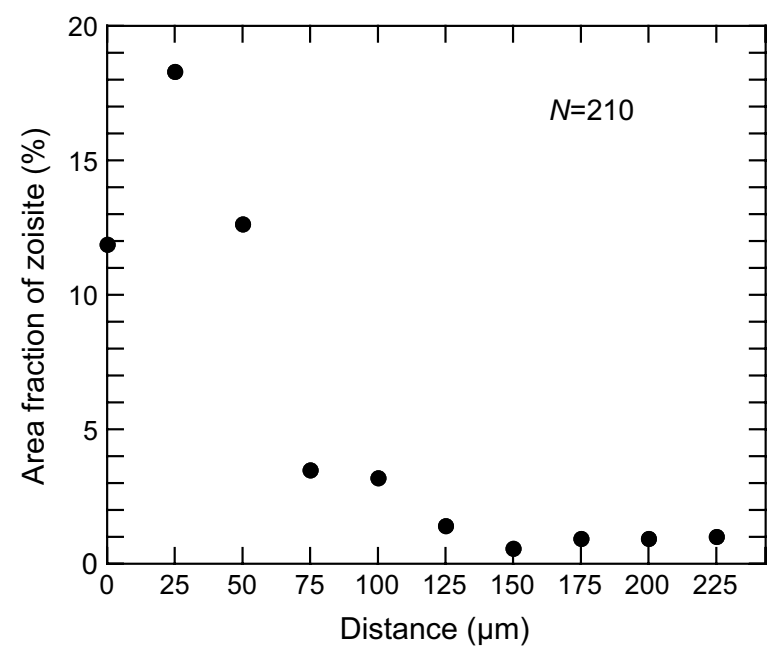

Fig. 7 Fractions of the zoisite grains visible under SEM images. The grains were traced at an interval of $25 \mu \mathrm{m}$ toward the upper part of the sample (e.g., see Fig. 6)

part of the sample. The water contents in wt ppm $\mathrm{H}_{2} \mathrm{O}$ were calculated via the calibration method of Paterson (1982) with $v_{\text {mean }}=3220 \mathrm{~cm}^{-1}$ and the density of zoisite $\left(3.35 \mathrm{~g} / \mathrm{cm}^{3}\right)$. Since the zoisite grains appear to be threedimensionally distributed, we used an isotropic orientation factor of $\gamma=1 / 3$. The calculated water content at the sample boundary is $1500 \mathrm{ppm}$ (the IR spectrum of No. 4 in Fig. 9c), which is notably the same amount of water added to the sample. In the non-deformed area, a broadband can be seen at $2800-3750 \mathrm{~cm}^{-1}$ corresponding to the stretching vibration of fluid $\mathrm{H}_{2} \mathrm{O}$. This band easily disappears by heating to approximately $100{ }^{\circ} \mathrm{C}$; therefore, this band is likely due to adsorbed atmospheric water.

Contrary to the results for the sample boundary, the side of the sample without bulging does not exhibit zoisite bands (Fig. 10). The area $\sim 200 \mu \mathrm{m}$ from the side is transparent and displays many developed cracks (Fig. 10a). In this area, only a broadband with a maximum at $3540 \mathrm{~cm}^{-1}$ and a shoulder of $3280 \mathrm{~cm}^{-1}$ can be seen. The former band could be due to the stretching vibration of water in the glass, and the latter as well as the broadband are likely due to water both in the glass and along the grain boundaries. The increases and decreases in these water-stretching bands correspond to those of the water-bending bands at approximately $1560 \mathrm{~cm}^{-1}$. The band features under $1800 \mathrm{~cm}^{-1}$, except for the waterbending bands, are due to the structural vibrations of anorthite, which are the same as those around the sample boundary (Fig. 9). Unlike the results for the sample boundary, the mapped area did not show a concentration gradient of water. This is likely due to many cracks (Fig. 10a), since water easily moves through cracks. A broadband at $2800-3750 \mathrm{~cm}^{-1}$, which is seen apart from the transparent area, is due to adsorbed water and is similar to the results around the sample boundary (Fig. 9). The water contents calculated with $v_{\text {mean }}=3350 \mathrm{~cm}^{-1}$ and the density of anorthite $\left(2.75 \mathrm{~g} / \mathrm{cm}^{3}\right)$ were 200 1000 ppm $\mathrm{H}_{2} \mathrm{O}$.

\section{Diffusion of water}

The diffusion coefficient of water in the water-added sample was determined from the gradient of the IR bands around the sample boundary (Fig. 9), which mainly showed water bands in zoisite formed by the reaction between anorthite and water (Eq. 1). The concentration profile of water, which was determined from No. 1-10 and their intermediate data in Fig. 9c, was well fitted to the solution of the one-dimensional diffusion equation as follows (Crank 1975, p. 21):

$$
C=C_{0} \operatorname{erfc}\left(\frac{x}{2 \sqrt{D t}}\right),
$$

where $C$ is the concentration at a distance $x$ from the sample boundary, $C_{0}$ is the maximum concentration, erfc is the complementary error function, $t$ is the time duration, and $D$ is the diffusion coefficient to be determined. The duration was $5 \mathrm{~h}$ at $900{ }^{\circ} \mathrm{C}$, which include the time for the pre-hit $(1 \mathrm{~h})$ and deformation $(4 \mathrm{~h})$. The distance of water diffusion was shortened by compression during the experiment: The distance $x$ from the sample boundary as measured by IR spectroscopy includes a strain of $\sim 40 \%$ according to microstructural observations (see Microstructural observations section). Therefore, we also calculated the diffusion coefficient at $x / 0.6$. The results are shown in Fig. 11, where the diffusion coefficients calculated with $x$ and $x / 0.6$ are shown as $D_{x}$ and $D_{x / 0.6}$, respectively, which were $D_{x}=7.4 \times 10^{-13} \mathrm{~m}^{2} / \mathrm{s}$ and $D_{x / 0.6}=2.1 \times 10^{-12} \mathrm{~m}^{2} / \mathrm{s}$. These two values are similar, and the true diffusion coefficient would be between the two. The profile of the water concentration is similar to that of the zoisite grains obtained from the BSE image (Fig. 7).

These two diffusion coefficients were compared with those reported previously in an Arrhenius diagram (Fig. 12). Farver and Yund (1995) doped $\mathrm{H}_{2}^{18} \mathrm{O}$ into orthoclase aggregates under $100 \mathrm{MPa}$ and $450-800{ }^{\circ} \mathrm{C}$, and they analyzed oxygen isotope profiles through ion microprobe analyses. They reported that the diffusing species at the grain boundaries is molecular water. The diffusion coefficients for volume diffusion in anorthite, orthoclase, and albite reported in Giletti et al. (1978) are also shown for comparison, and they are also similar. The authors of the study of Giletti et al. (1978) doped $\mathrm{H}_{2}^{18} \mathrm{O}$ into single crystals and analyzed ${ }^{18} \mathrm{O}$ profiles similar to the experiments in Farver and Yund (1995). The diffusing species 


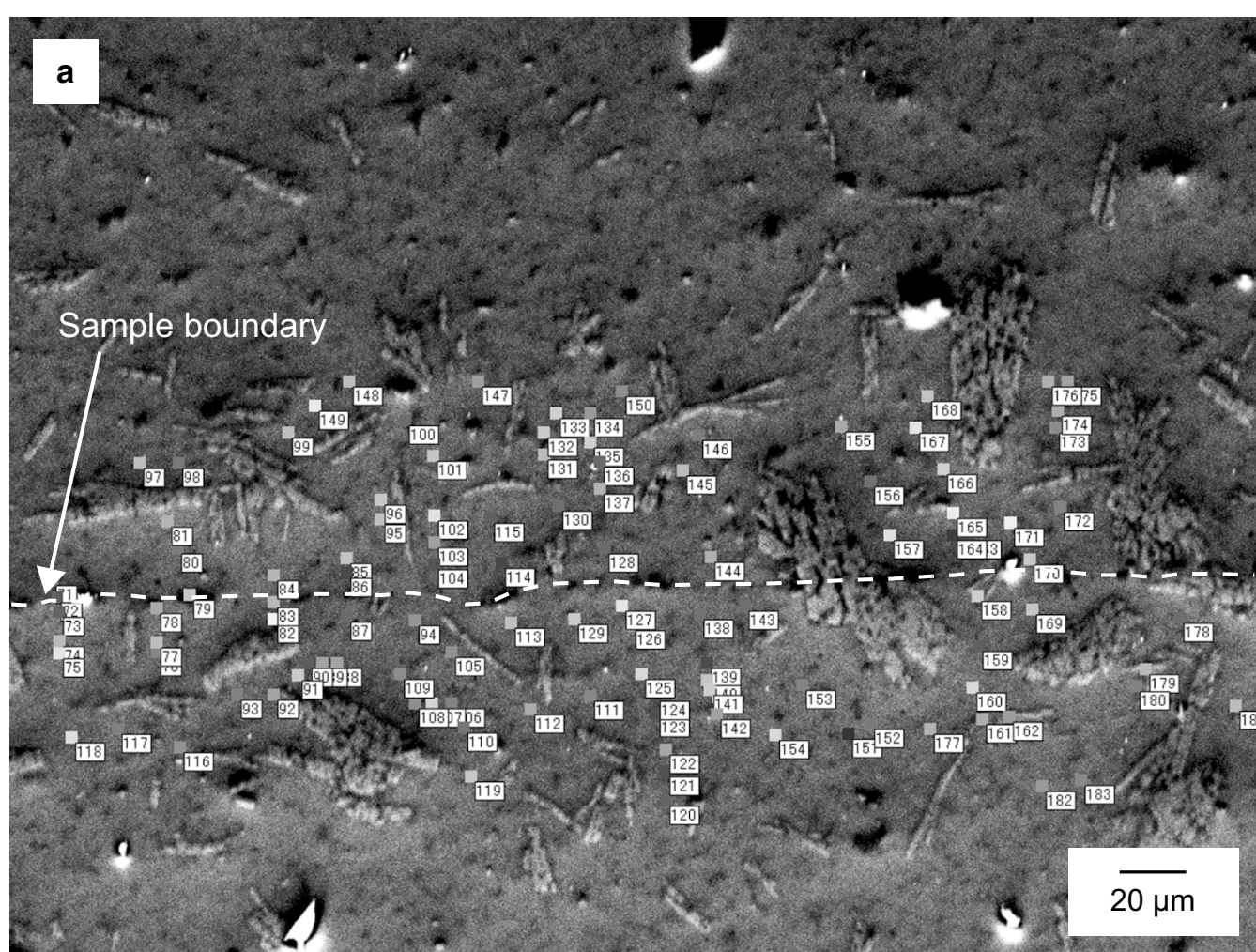

b

(100)

Z

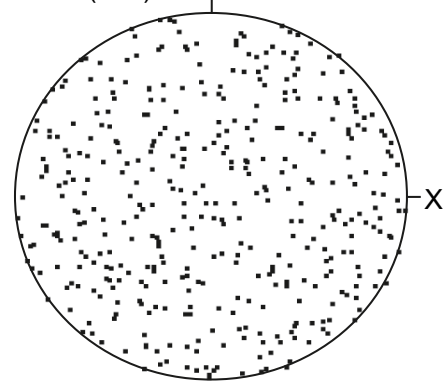

(010)

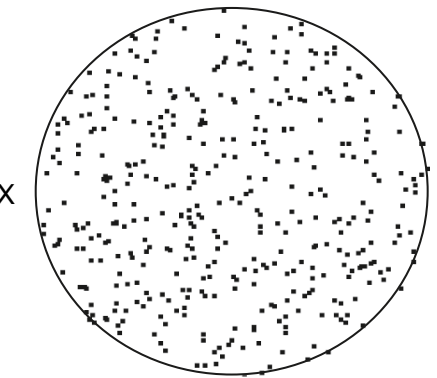

(001)

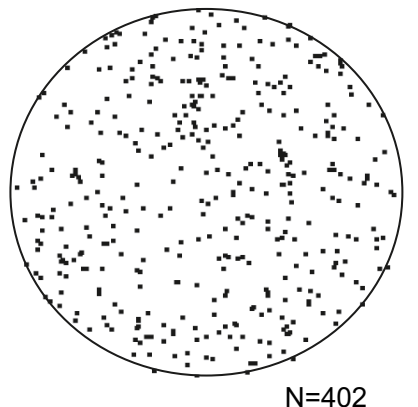

Fig. 8 EBSD measurement results for anorthite grains in the water-added sample. a Example of point analysis in a BSE image. The measurements were taken within $50 \mu \mathrm{m}$ of the upper and lower sample boundaries (white dashed lines). b Pole figures for the representative crystallographic planes at an equal-area and lower hemisphere projection. Elongation (i.e., bulging) and shortening directions are denoted as $X$ and $Z$, respectively

were not clearly documented in Giletti et al. (1978), but they were believed to be molecular water in similar experiments for single orthoclase crystals in Farver and Yund (1990). The diffusion coefficients for grain boundary diffusion are much higher than those for volume diffusion. Our diffusion coefficient determined from the zoisite absorption bands is plotted near the extrapolated line of grain boundary diffusion for orthoclase as reported by Farver and Yund (1995).

\section{Discussion}

Enhancement and localization of plastic deformation by water

Previous studies that uniformly deformed samples and observed steady states of stress have confirmed that strength reduction can be achieved via added water (e.g., Kronenberg and Tullis 1984; Post and Tullis 1998; Chernak et al. 2009). In contrast, in our water-added experiment, the calculated strain in the bulging part (Fig. 5) was 

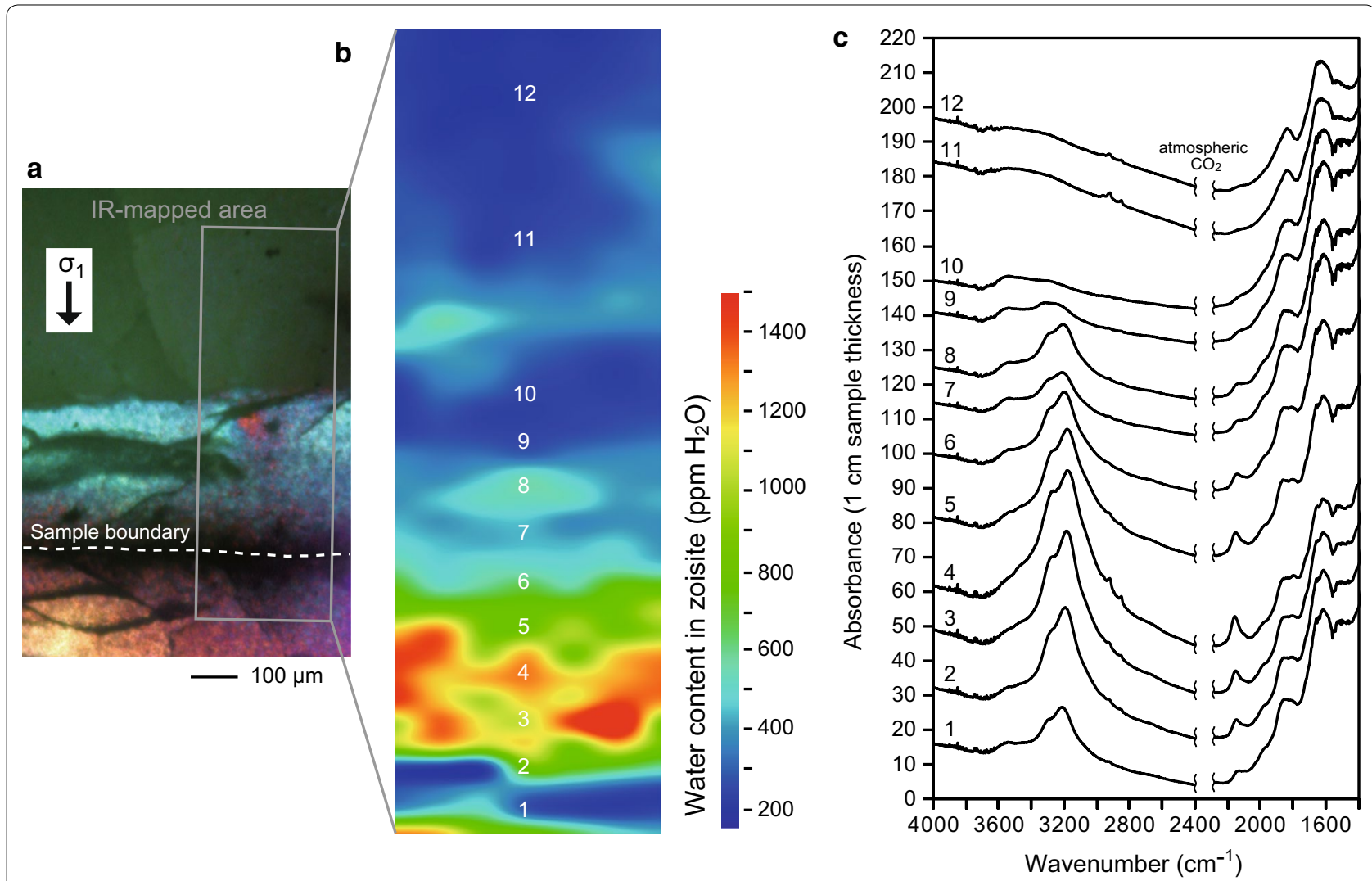

Fig. 9 IR mapping results for the upper and lower sample boundaries of the water-added experiment. a Optical image (cross-polarized light with a gypsum plate). The compression direction $\left(\sigma_{1}\right)$ is shown by an arrow. The upper and lower sample boundaries are shown as white dashed lines. The IR-mapped area is shown as a gray rectangle. b IR mapping results shown as water contents in zoisite. c Raw IR spectra selected from (b). The numbers correspond to the parts in (b). The IR spectrum for the sample boundary corresponds to the No. 4 spectrum, and the calculated water content was $1500 \mathrm{ppm} \mathrm{H}_{2} \mathrm{O}$

$\sim 40 \%$, which is approximately four times the permanent strain of $12 \%$ when assuming homogenous deformation in the mechanical data (Fig. 3). The compressive flow strength of a laminated rock composed of two phases is directional (e.g., Ji et al. 2000). For a layer composite with interface planes normal to the compressive axis, those two phases are subjected to equal stresses (and different strain rates; Reuss bound). The higher strain in the bulging part indicates that the strain rate at the same deformation time was four times higher than the bulk sample and that deformation was localized by water diffusion, implying that the effective viscosity ( stress/strain rate) of the water-diffused part was lower than that of the initial dry part. This would be due to the limited width of the water-diffused part $(\sim 250 \mu \mathrm{m}$ both upward and downward in the two cores with total lengths of $\sim 9 \mathrm{~mm}$; Fig. 5). In contrast, cataclasis dominated in the dry sample (Fig. 4). The strengths between the dry and wet experiments were not different (Fig. 3). Consequently, the strengths of the bulging and dry parts in the water-added sample were not different, and the measured sample bulk strength may not have been different from that of the dry sample.

In the water-added sample, zoisite grains up to $50 \mu \mathrm{m}$ are observed as a reaction product (Fig. 6). They separately exist, and each grain is fractured. Therefore, zoisite does not directly contribute to the deformation, as was also documented in Stünitz and Tullis (2001). The $\mathrm{SiO}_{2}$ domain is partially connected (Fig. 6). According to Spiess et al. (2012), such a domain, which is different from the initial glass with high silica and aluminum contents in our case (Fig. 1), might have been formed by dissolution and precipitation in open spaces. The precipitated grains might have been caused by the reaction in Eq. (1), but they could also have been due to the glass initially included in the sample (Fig. 1). We did not observe a segregation of the glass similar to Dimanov et al. (1998, 2000), who performed axial deformation experiments on homogeneously wet plagioclase aggregates with melt reaching up to $12 \mathrm{vol} \%$. Diffused water, which can cause a reaction in anorthite, is incorporated in the original glass in our sample. The IR spectra for the water-added 


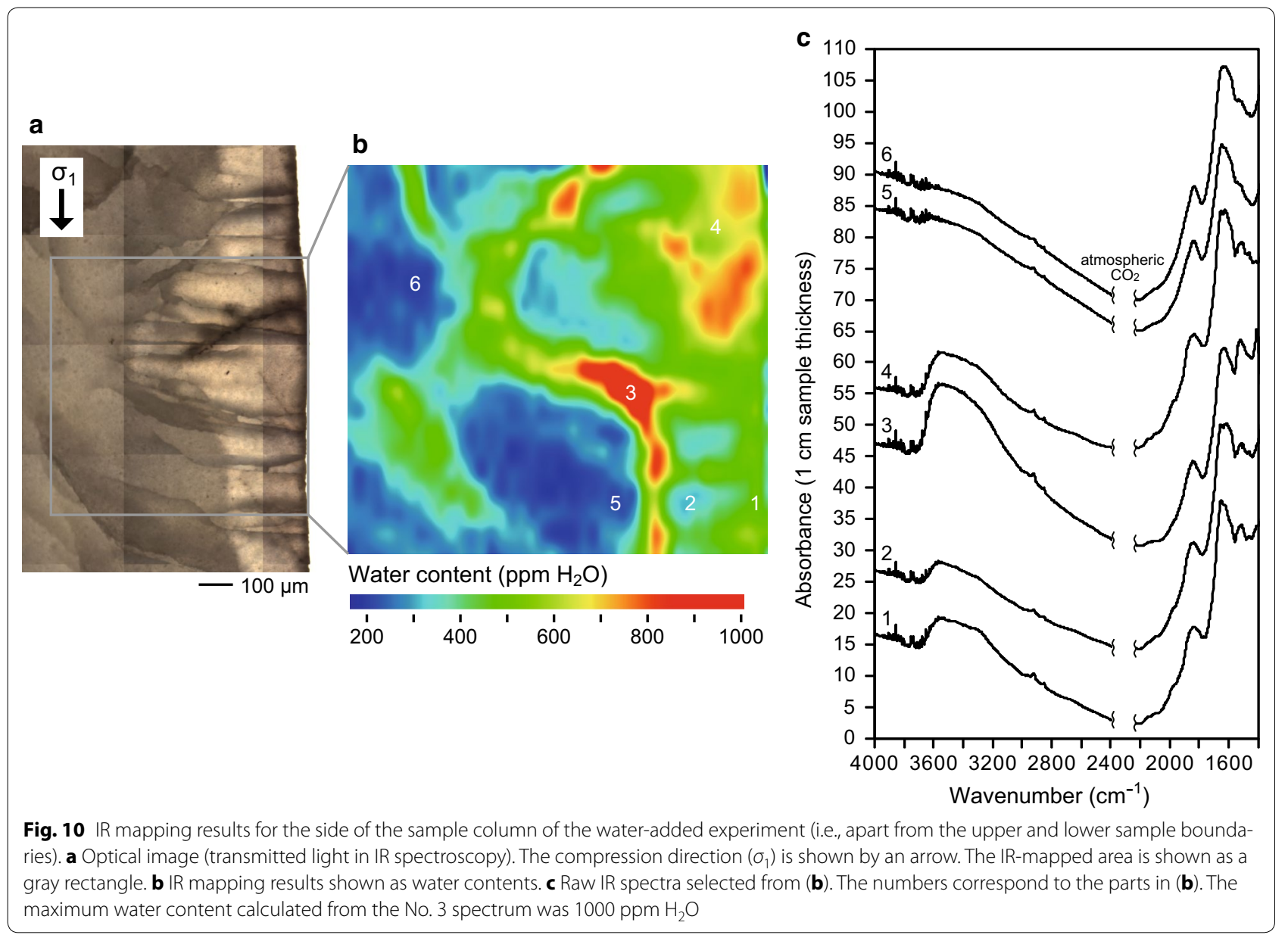

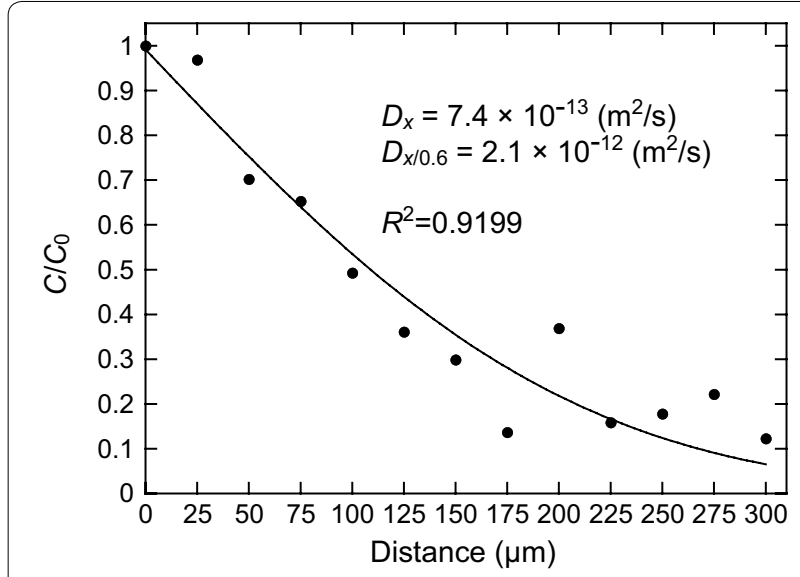

Fig. 11 Determination of the diffusion coefficients in the wateradded deformation experiment. The water contents and distance correspond to the water absorption bands in Fig. 9, and the diffusion coefficient is shown as $D_{x}$. The diffusion coefficient for the initial sample length without $40 \%$ strain $\left(D_{x / 0.6}\right)$ is also shown for comparison. The coefficient of determination $\left(R^{2}\right)$ is shown sample show that the band due to glass has a maximum at $3540 \mathrm{~cm}^{-1}$ around the sample boundary (Fig. 9) and especially the side of the sample column (Fig. 10). The incorporation of water into the melt as well as the inclusion of water along the anorthite grain boundaries contributes to the strength of the sample, although the overall quantitative effect is difficult to estimate in this study. The water contents along the side of the sample column reach up to $1000 \mathrm{ppm} \mathrm{H}_{2} \mathrm{O}$, indicating the presence of saturated water trapped in the glass and along the anorthite grain boundaries.

The profile of the water concentration (Fig. 11) is similar to that of the zoisite distribution (Fig. 7). IR spectra from the upper and lower sample boundaries show that water is dominantly trapped within the zoisite (Fig. 9). Assuming a $2.0 \mathrm{wt} \% \mathrm{H}_{2} \mathrm{O}$ stoichiometric amount of water in a zoisite crystal structure (e.g., Hurlbut 1969), the representative zoisite area fractions of $18.3 \%$ (maximum at $25 \mu \mathrm{m}$ from the upper and lower sample boundaries), $12.6 \%(50 \mu \mathrm{m}), 3.5 \%(75 \mu \mathrm{m})$, and $0.9 \%(200 \mu \mathrm{m})$ 


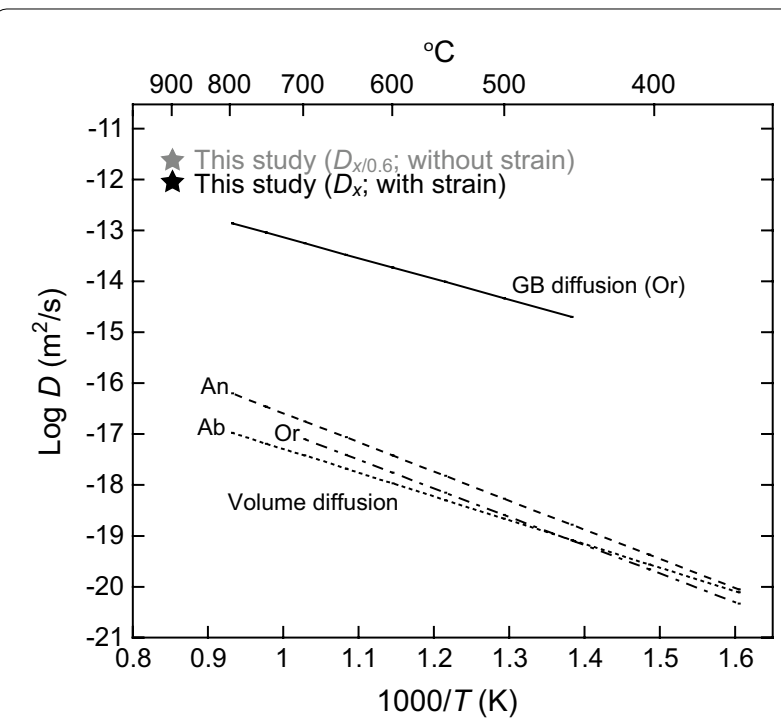

Fig. 12 Comparison of the diffusion coefficients of feldspar in an Arrhenius diagram. The values determined in this study with and without $40 \%$ strain are shown as black and gray stars, respectively. The values of the volume diffusion and grain boundary diffusion coefficients were taken from Giletti et al. (1978) and Farver and Yund (1995), respectively. An anorthite; Or orthoclase; Ab albite

shown in Fig. 7 can be converted into 3700, 2520, 700, and $180 \mathrm{ppm} \mathrm{H}_{2} \mathrm{O}$, respectively. These converted water contents roughly correspond to the values measured via IR spectroscopy (1500 ppm at the maximum at the sample boundary; Fig. 9). However, fine zoisite grains also develop along the anorthite grain boundaries (Fig. 6c). The quantity of these fine grains would also be high along the sample boundaries, and water would also be trapped in these grains.

The deformation of the feldspar group by reactions involving solution-precipitation creep has been reported for naturally deformed samples under lower-middle crustal conditions (Fitz Gerald and Stünitz 1993; Ree et al. 2005; Menegon et al. 2008; Brander et al. 2012; Fukuda et al. 2012). In such cases, the fluid phase was likely supplied externally. Our study provides information on fabric development and strain localization during the water-introduction process. The anorthite grains in the water-added experiment would have been partially dissolved in the reaction in Eq. (1), which is also indicated by the vermicular features (Fig. 6d). The crystallographic orientation of anorthite was random in the bulging portion, indicating the presence of grain-size-sensitive creep in the anorthite aggregate (Fig. 8). The IR spectra around the bulging part show stretching bands of mainly hydroxyl in the zoisite (Fig. 9). Thus, the localization of plastic deformation is directly related to the diffusion of water into the sample, even though the mechanical data between the dry and water-added experiments may be identical (Fig. 3). Thus, when water is introduced into dry polycrystalline anorthite, its deformation mechanism switches from cataclastic flow to plastic flow due to grainsize-sensitive creep assisted by the reaction and melt, thereby causing strain localization. Melt-assisted grainsize-sensitive creep was also confirmed by Dell'Angelo et al. (1987) for fine-grained granitic aggregates with melt contents of 3-5\% via transmission electron microscopy; in those samples, the deformation switched from the dislocation creep of quartz and feldspar with a melt content of $<1 \%$.

\section{Implications for crustal dynamics}

The existence of fluid in the crust has been inferred from tomographic studies (e.g., Ogawa et al. 2001; Okada et al. 2006; Wannamaker et al. 2009; Nakajima et al. 2010; Becken et al. 2011 and references therein). The recent studies by Okudaira et al. $(2015,2017)$ reported fractured plagioclase grains that were likely formed at lower-crustal conditions based on microstructural observations and analyses for naturally deformed gabbroic and anorthositic rocks. They suggested that fracturing and subsequent fluid infiltration are locally possible in the lower crust. Our study demonstrated that the enhancement of plastic deformation in initially dry feldspar could be governed by water diffusion. In the lower-middle crust, water would diffuse into a rock mass through pathways such as fractures, which may be produced mechanically and/or by over-pressurized water (i.e., fluid fissures; Wannamaker et al. 2009), thereby inducing plastic deformation where water is introduced (Fig. 5). Note that this study focuses on the localization and development of plastic deformation by water diffusion under a given stress regime, which could lead to grain-size-sensitive creep accompanied by a reaction. Figure 13 shows a schematic image of the temporal evolution of the waterdiffusion-controlled deformation of an initially dry rock mass. Under a compressive stress field, water is supplied to the dry system through fractures at a deformation time $t=t_{0}$. Water diffuses into the rock mass simultaneous with the initiation of water-diffusion-controlled deformation, and the rock then deforms with time $\left(t=t_{1}\right.$ and $t_{2}$ in Fig. 13). The flow laws for different water contents should essentially describe the corresponding deformation, although previously reported flow laws for feldspar have been experientially determined only for samples with specific water contents or for dry samples (Dimanov et al. 1998, 1999, 2000; Rybacki and Dresen 2004; Rybacki et al. 2006). We estimated the evolution of the strain rate in a rock mass controlled by water diffusion. For onedimensional deformation, the strain rate is simply written

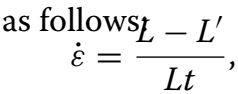




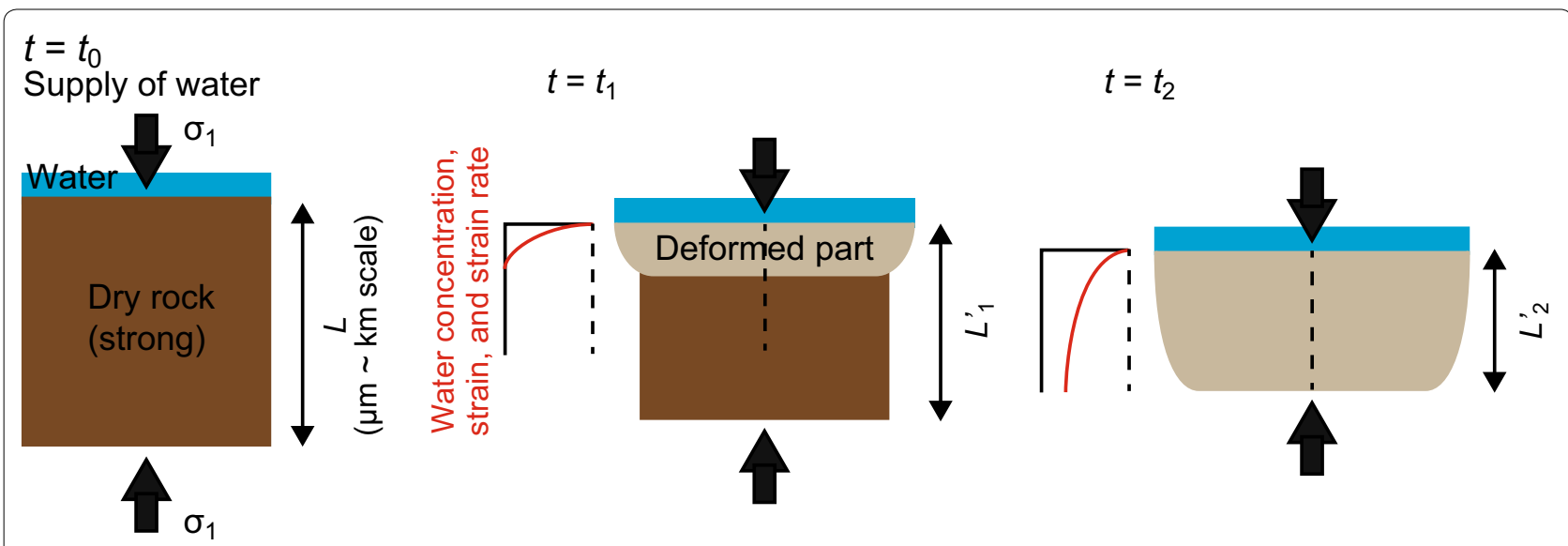

Fig. 13 Schematic image of water diffusion into a rock mass and the development of water-diffusion-controlled deformation. Profiles of the water concentration, strain, and strain rate (shown by red solid lines) for regions of non-deformed dry rock mass and shortened rock mass by water diffusion (shown by dashed lines) at $t=t_{1}$ and $t_{2}$. See details in the text

where $\dot{\varepsilon}$ is the strain rate, $L$ is the initial width of the dry rock mass into which water is introduced, $L^{\prime}$ is the width of the rock mass following plastic deformation under a given deformation time $t$ (denoted as $L_{1}^{\prime}$ and $L_{2}^{\prime}$ at $t_{1}$ and $t_{2}$, respectively, in Fig. 13). These two widths could vary from microstructural in size (Okudaira et al. 2015, 2017) to geological in scale (Wannamaker et al. 2009). The deformation time is equal to the time that water takes to diffuse into the rock mass. Then, $L-L^{\prime}$ can be rewritten as the water diffusion distance $x$ in Eq. (2). This means that plastic deformation begins from the contact between the rock and water to the distance $x$. The $x$ value at $C / C_{0}=0.1$ in Eq. (2) is commonly used (i.e., $x=2.3 \sqrt{D t}=L-L^{\prime}$ ) because $x$ mathematically diverges at $C / C_{0} \approx 0$. This value is realistic for the bulging portion, which was observed under a polarizing optical microscope (Fig. 5) and in the IR spectroscopic measurements (Fig. 9). The strain rate in Eq. (3) is determined by the deformation induced by water diffusion under a given stress. A diffusion coefficient of $10^{-13} \mathrm{~m}^{2} / \mathrm{s}$ was used because it does not significantly change in the temperature conditions of the lower-middle crust from 500 to $800{ }^{\circ} \mathrm{C}$ (Farver and Yund 1995) (Fig. 12). Various rock mass scales at which water diffusion occurs can be considered in nature. Therefore, we applied the above approach to rock mass scales from $0.1 \mathrm{~m}$ to $1 \mathrm{~km}$ as well as over a temporal evolution from 0.1 to 10,000 years.

Figure 14 shows the evolution of the strain rate under different scales of the rock mass and temporal evolution. When the width of the initial rock mass is small (e.g., $<1 \mathrm{~m}$ ), water is introduced to a relatively large part of the rock mass. As a result, the rock mass deforms with a high strain rate on the order of $\sim 10^{-10} \mathrm{~s}^{-1}$ at the early stage of water diffusion. When the rock mass size is larger, the deformable part (i.e., the water diffusion distance with respect to the size of the rock mass) is relatively smaller than that for a smaller rock mass under the same $t$. In this case, the strain rate becomes lower. For a constant rock mass width, an increase in the time taken for water diffusion allows for larger widths to be deformed, leading to a decrease in the strain rate. In other words, the strain is distributed at long distances in the rock mass at low strain rates. Then, the strain rate changes from $10^{-10}$ to $10^{-15} \mathrm{~s}^{-1}$ with an increase in the time span up to 10,000 years (Fig. 14). In the lower-middle crust, where fluid can be supplied to the system, the strain rate can be locally high at the deformable part where water is introduced and decrease with time as the deformed area develops. The calculated strain rate controlled by water

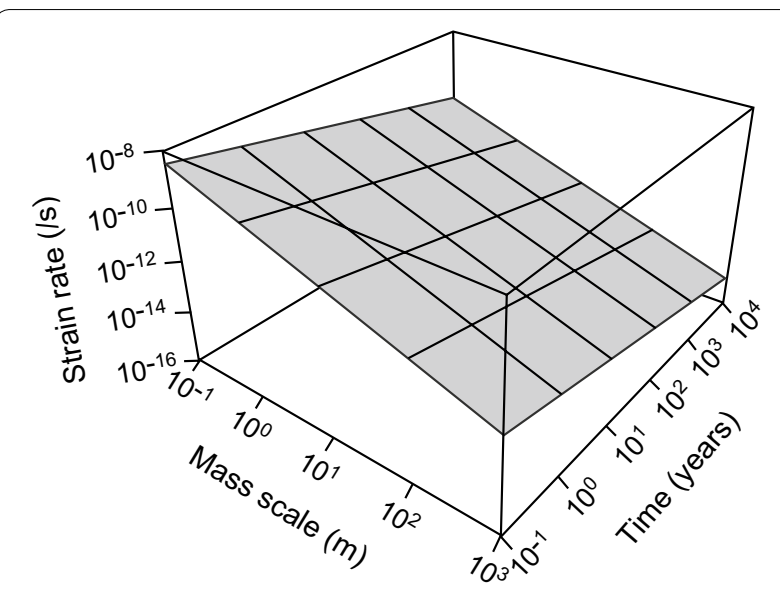

Fig. 14 Evolution of the strain rate controlled by water diffusion for different rock masses and time scales 
diffusion gives reasonable geological values. Based on our experiments, textural observations and analyses, the evolution of the strain rate can provide physical insights on water reservoirs in the lower-middle crust. Thus, in nature, a wide range of strain rates can be possible at various rock scales into which water diffuses.

\section{Conclusions}

We performed deformation experiments on polycrystalline anorthite samples both with and without water. Fractures dominated in the dry experiments, while plastic deformation occurred in the $0.15 \mathrm{wt} \%$ water-added experiment and was concentrated within the water-diffused area. Zoisite was formed as the reaction product, and water was incorporated within it. The maximum water content was 1500 wt ppm $\mathrm{H}_{2} \mathrm{O}$, which is consistent with the amount of added water, and the water contents gradually decreased toward the inner part of the sample. The profile of the water concentration gradient fits well with the solution of one-dimensional diffusion. The determined diffusion coefficient was $\sim 10^{-12} \mathrm{~m}^{2} / \mathrm{s}$, which agrees with previous data. We calculated the evolution of the plastic deformation strain rate controlled by water diffusion at different rock mass and temporal scales under lower-middle crustal conditions with a representative water diffusion coefficient of $10^{-13} \mathrm{~m}^{2} / \mathrm{s}$. The calculated water-diffusion-based strain rates were within a geologically reasonable range from $10^{-10}$ to $10^{-15} \mathrm{~s}^{-1}$ at rock mass scales from $<1 \mathrm{~m}$ to $1 \mathrm{~km}$ with a temporal increase from $<1$ year to 10,000 years. This implies that water diffusion likely controls the deformation of the initially dry and strong lower-middle crust.

\section{Authors' contributions}

JM performed the deformation experiments. JF performed all of the analyses and drafted the main part of the manuscript. JF, JM, and HN interpreted all of the data and drafted the manuscript.

\section{Author details}

${ }^{1}$ Department of Earth Science, Tohoku University, 6-3 Aoba-ku, Sendai, Miyagi 980-8578, Japan. ${ }^{2}$ Department of Earth and Planetary Science, The University of Tokyo, Bunkyo-ku, Tokyo 113-0033, Japan. ${ }^{3}$ Institut des Sciences de la Terre d'Orléans, UMR 7327, Université d'Orléans, 1a rue de la Férollerie, 45071 Orléans, France.

\section{Acknowledgements}

The authors thank J. Tullis, G. Hirth, and R. Cooper for their experimental support at Brown University and M. Nakamura and S. Okumura for conducting the IR measurements at Tohoku University. Detailed reviews by T. Okudaira and two anonymous reviewers greatly improved the manuscript. We also thank T. Takeshita for his editorial handling and comments.

\section{Competing interests}

The authors declare that they have no competing interests.

\section{Ethics approval and consent to participate}

Not applicable.

\section{Funding}

JF was supported financially by a Grant-in-Aid for Scientific Research for Young Scientists (233694) provided by the Japan Society of the Promotion of Science
(JSPS), by a Grant-in-Aid provided by the Fukada Geological Institute, and by MEXT KAKENHI grant (15K21755). In addition, this work was supported financially by MEXT KAKENHI grant (26109005) to JM.

\section{Publisher's Note}

Springer Nature remains neutral with regard to jurisdictional claims in published maps and institutional affiliations.

Received: 31 March 2017 Accepted: 26 December 2017

Published online: 04 January 2018

\section{References}

Becken M, Ritter O, Bedrosian PA, Weckmann U (2011) Correlation between deep fluids, tremor and creep along the central San Andreas fault. Nature 480:87-90

Beran A (1987) OH groups in nominally anhydrous framework structures: an infrared spectroscopic investigation of danburite and labradorite. Phys Chem Mineral 14:441-445

Brander L, Svahnberg H, Piazolo S (2012) Brittle-plastic deformation in initially dry rocks at fluid-present conditions: transient behaviour of feldspar at mid-crustal levels. Contrib Mineral Petrol 163:403-425

Bürgmann R, Dresen G (2008) Theology of the lower crust and upper mantle: evidence from rock mechanics, geodesy, and field observations. Annu Rev Earth Planet 36:531-567

Chernak LJ, Hirth G, Selverstone J, Tullis J (2009) Effect of aqueous and carbonic fluids on dislocation creep strength of quartz. J Geophys Res 114:B04201

Crank J (1975) The mathematics of diffusion, 2nd edn. Oxford University Press, New York, p 21

Dell'Angelo LN, Tullis J, Yund RA (1987) Transition from dislocation creep to melt-enhanced diffusion creep in fine-grained granitic aggregates. Tectonophysics 139:325-332

Den Brok B, Spiers CJ (1991) Experimental evidence for water weakening of quartzite by microcracking plus solution-precipitation creep. J Geol Soc Lond 148:541-548

Den Brok B, Meinecke J, Röller K (1994) Fourier transform IR-determination of intragranular water content in quartzites experimentally deformed with and without added water in the ductile deformation field. J Geophys Res 99:19821-19828

Dimanov A, Dresen G, Wirth R (1998) High-temperature creep of partially molten plagioclase aggregates. J Geophys Res 103:9651-9664

Dimanov A, Dresen G, Xiao X, Wirth R (1999) Grain boundary diffusion creep of synthetic anorthite aggregates: the effect of water. J Geophys Res 104:10483-10497

Dimanov A, Dresen G, Wirth R (2000) The effect of melt distribution on the rheology of plagioclase rocks. Tectonophysics 328:307-327

Farver JR, Yund RA (1990) The effect of hydrogen, oxygen, and water fugacity on oxygen diffusion in alkali feldspar. Geochim Cosmochim Acta 54:2953-2964

Farver JR, Yund RA (1995) Grain boundary diffusion of oxygen, potassium and calcium in natural and hot-pressed feldspar aggregates. Contrib Mineral Petrol 118:340-355

Fitz Gerald JD, Stünitz H (1993) Deformation of granitoids at low metamorphic grade. I: reactions and grain size reduction. Tectonophysics 221:269-297

Fukuda J, Okudaira T (2013) Grain-size-sensitive creep of plagioclase accompanied by solution-precipitation and mass transfer under mid-crustal conditions. J Struct Geol 51:61-73

Fukuda J, Okudaira T, Satsukawa T, Michibayashi K (2012) Solution-precipitation of K-feldspar in deformed granitoids and its relationship to the distribution of water. Tectonophysics 532-535:175-185

Getsinger AJ, Hirth G, Stünitz H, Goergen ET (2013) Influence of water on rheology and strain localization in lower continental crust. Geochem Geophys Geosyst 14:2247-2264

Giletti BJ, Semet MP, Yund RA (1978) Studies in diffusion-III. Oxygen in feldspars: an ion microprobe determination. Geochim Cosmochim Acta 42:45-57 
Goldsmith J (1982) Plagioclase stability at elevated temperatures and water pressures. Am Mineral 67:653-675

Hacker BR, Abers GA (2004) Subduction factory 3: an excel worksheet and macro for calculation the densities, seismic wave speeds, and $\mathrm{H}_{2} \mathrm{O}$ contents of minerals and rocks at pressure and temperature. Geochem Geophys Geosyst 5:Q01005

Heidelbach F, Post A, Tullis J (2000) Crystallographic preferred orientation in albite samples deformed experimentally by dislocation and solution precipitation creep. J Struct Geol 22:1649-1661

Holyoke CW, Kronenberg AK (2010) Accurate differential stress measurement using molten salt cell and solid salt assemblies in the Griggs apparatus with applications to strength, parameters and rheology. Tectonophysics 494:17-31

Hurlbut CS (1969) Gem zoisite from Tanzania. Am Mineral 54:702-709

Ji S, Wirth R, Rybacki E, Jiang Z (2000) High-temperature plastic deformation of quartz-plagioclase multilayers by layer-normal compression. J Geophys Res 105:16651-16664

Jiang Z, Prior DJ, Wheeler J (2000) Albite crystallographic preferred orientation and grain misorientation distribution in a low-grade mylonite: implications for granular flow. J Struct Geol 22:1663-1674

Johnson E, Rossman GR (2003) The concentration and speciation of hydrogen in feldspars using FTIR and ${ }^{1} H$ MAS NMR spectroscopy. Am Mineral 88:901-911

Kido M, Muto J, Nagahama H (2016) Method for correction of differential stress calculations from experiments using the solid salt assembly in a Griggstype deformation apparatus. Tectonophysics 672-673:170-176

Kohlstedt DL, Evans B, Mackwell SJ (1995) Strength of the lithosphere: constraints imposed by laboratory experiments. J Geophys Res 100:17587-17602

Kronenberg AK, Tullis J (1984) Flow strengths of quartz aggregates: grain size and pressure effects due to hydrolytic weakening. J Geophys Res 89:4281-4297

Kruhl JH (1987) Preferred lattice orientations of plagioclase from amphibolite and greenschist facies rocks near the Insubric Line (Western Alps). Tectonophysics 135:233-242

Kruse R, Stünitz H, Kunze K (2001) Dynamic recrystallization processes in plagioclase porphyroclasts. J Struct Geol 23:1781-1802

Langer K, Lattard D (1980) Identification of a low-energy OH-valence vibration in zoisite. Am Mineral 65:779-783

Matthews A, Goldsmith JR (1984) The influence of metastability on reaction kinetics involving zoisite formation from anorthite at elevated pressures and temperatures. Am Mineral 69:848-857

Menegon L, Pennacchioni G, Spiess R (2008) Dissolution-precipitation creep of K-feldspar in mid-crustal granite mylonites. J Struct Geol 30:565-579

Menegon L, Fusseis F, Stünitz H, Xiao X (2015) Creep cavitation bands control porosity and fluid flow in lower crustal shear zones. Geology 43:227-230

Nakajima J, Kato A, Iwasaki T, Ohmi S, Okada T, Takeda T, The Japanese University Group of the Joint Seismic Observations at NKTZ (2010) Deep crustal structure around the Atotsugawa fault system, central Japan: a weak zone below the seismogenic zone and its role in earthquake generation. Earth Planets Space 62:555-566

Ogawa Y, Mishina M, Goto T, Satoh H, Oshiman N, Kasaya T, Takahashi Y, Nishitani T, Sakanaka S, Uyeshima M, Takahashi Y, Honkura Y, Matsushima M (2001) Magnetotelluric imaging of fluids in intraplate earthquake zones, NE Japan back arc. Geophys Res Lett 28:3741-3744

Okada T, Yaginuma T, Umino N, Matsuzawa T, Hasegawa A, Zhang H, Thurber CH (2006) Detailed imaging of the fault planes of the 2004 NiigataChuetsu, central Japan, earthquake sequence by double-difference tomography. Earth Planet Sci Lett 244:32-43

Okudaira T, Jeřábek P, Stünitz H, Fusseis F (2015) High-temperature fracturing and subsequent grain-size-sensitive creep in lower crustal gabbros: evidence for coseismic loading followed by creep during decaying stress in the lower crust? J Geophys Res 120:3119-3141

Okudaira T, Shigematsu N, Harigane Y, Yoshida K (2017) Grain size reduction due to fracturing and subsequent grain-size-sensitive creep in a lower crustal shear zone in the presence of a $\mathrm{CO}_{2}$-bearing fluid. J Struct $\mathrm{Geol}$ 95:171-187
Olsen TS, Kohlstedt D (1985) Natural deformation and recrystallization of some intermediate plagioclase feldspars. Tectonophysics 111:107-131

Paterson MS (1982) The determination of hydroxyl by infrared absorption in quartz, silicate glasses and similar materials. Bull Mineral 105:20-29

Post A, Tullis J (1998) The rate of water penetration in experimentally deformed quartzite: implications for hydrolytic weakening. Tectonophysics 295:117-137

Post A, Tullis J, Yund R (1996) Effects of chemical environment on dislocation creep of quartzite. J Geophys Res 101:22143-22155

Prior JD, Wheeler J (1999) Feldspar fabrics in a greenschist facies albite-rich mylonite from electron backscatter diffraction. Tectonophysics 303:29-49

Raimbourg H, Toyoshima T, Harima Y, Kimura G (2008) Grain-size reduction mechanisms and rheological consequences in high-temperature gabbro mylonites of Hidaka, Japan. Earth Planet Sci Lett 267:637-653

Ree JH, Kim HS, Han R, Jung H (2005) Grain-size reduction of feldspars by fracturing and neocrystallization in a low-grade granitic mylonite and its rheological effect. Tectonophysics 407:227-237

Rutter EH, Brodie KH (1988) The role of tectonic grain size reduction in the rheological stratification of the lithosphere. Geol Rundsch 77:295-308

Rybacki E, Dresen D (2004) Deformation mechanism maps for feldspar rocks. Tectonophysics 382:173-187

Rybacki E, Gottschalk M, Wirth R, Dresen G (2006) Influence of water fugacity and activation volume on the flow properties of fine-grained anorthite aggregates. J Geophys Res 111:B03203

Rybacki E, Wirth R, Dresen G (2008) High-strain creep of feldspar rocks: implications for cavitation and ductile failure in the lower crust. Geophys Res Lett 35:L04304

Rybacki E, Wirth R, Dresen G (2010) Superplasticity and ductile fracture of synthetic feldspar deformed to large strain. J Geophys Res 115:B08209

Spiess R, Dibona R, Rybacki E, Wirth R, Dresen G (2012) Depressurized cavities within high-strain shear zones: their role in the segregation and flow of $\mathrm{SiO}_{2}$-rich melt in feldspar-dominated rocks. J Petrol 53:1767-1776

Stolper E (1982) Water in silicate glasses: an infrared spectroscopy study. Contrib Mineral Petrol 81:1-17

Stünitz H, Tullis J (2001) Weakening and strain localization produced by syndeformational reaction of plagioclase. Int J Earth Sci 90:136-148

Stünitz H, Fitz Gerald JD, Tullis J (2003) Dislocation generation, slip systems, and dynamic recrystallization in experimentally deformed plagioclase single crystals. Tectonophysics 372:215-233

Tullis J, Yund RA (1987) Transition from cataclastic flow to dislocation creep of feldspar: mechanisms and microstructures. Geology 15:606-609

Tullis J, Yund RA (1991) Diffusion creep in feldspar aggregates: experimental evidence. J Struct Geol 13:987-1000

Vernooij MGC, den Brok B, Kunze K (2006) Development of crystallographic preferred orientations by nucleation and growth of new grains in experimentally deformed quartz single crystals. Tectonophysics 427:35-53

Wannamaker PE, Caldwell G, Jiracek GR, Maris V, Hill GJ, Ogawa Y, Bibby HM, Bennie SL, Heise W (2009) Fluid and deformation regime of an advancing subduction system at Marlborough, New Zealand. Nature 460:733-737

\section{Submit your manuscript to a SpringerOpen ${ }^{\circ}$ journal and benefit from:}

- Convenient online submission

- Rigorous peer review

- Open access: articles freely available online

- High visibility within the field

Retaining the copyright to your article

Submit your next manuscript at $\boldsymbol{\nabla}$ springeropen.com 